\title{
A patient with angina (2009: 4a)
}

(C) European Society of Radiology 2008

\section{Case report}

A 55-year-old woman was admitted with substernal squeezing pain for $10 \mathrm{~min}$. The patient had a past medical history of bronchiectasis and bronchial asthma for about 24 years. There had been several episodes of cold sweating with or without dyspnea during the last 5 years. Each time she was admitted and received conservative therapy. One year ago, the patient was admitted for haemoptysis $(150 \mathrm{ml} /$ day). Chest CT revealed severe bronchiectasis in both lobes and a focal area of consolidation in the left upper lobe (Fig. 1). The electrocardiogram (ECG) showed sinus rhythm and T-wave inversion in lead III and V1-6. The following day the ECG was much improved. The isolated organism from sputum and bronchoalveolar lavage fluid was Pseudomonas aerusinosa. The patient was treated with antibiotic therapy. Haemoptysis ceased spontaneously, so bronchial angiography with embolisation was not performed at that time.

The ECG performed on the most recent admission showed sinus rhythm but T-wave inversion in lead V1-3. Myocardial enzyme examination showed the following values: CK-MB, $11.9 \mathrm{IU} / 1$ (normal range, 0.6-6.3 IU/l); myoglobin, $18.2 \mathrm{ng} / \mathrm{ml}$ (normal range, 14.3-65.3 ng/ml); troponin-I, $0.02 \mathrm{ng} / \mathrm{ml}$

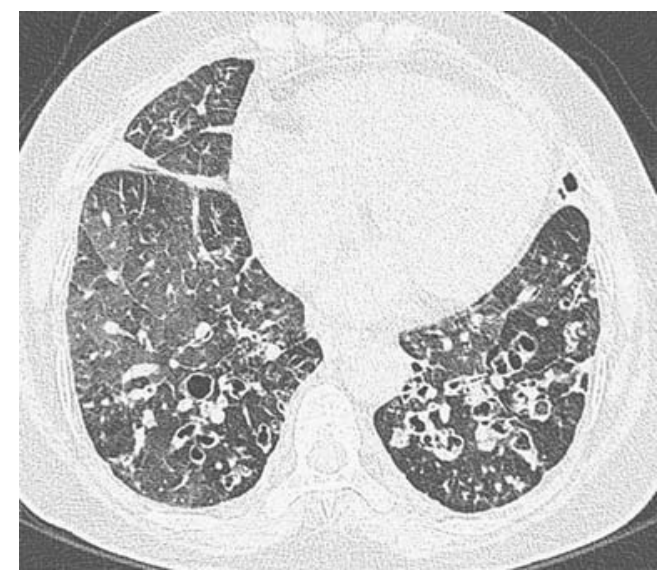

Fig. 1 Chest CT obtained 1 year before admission

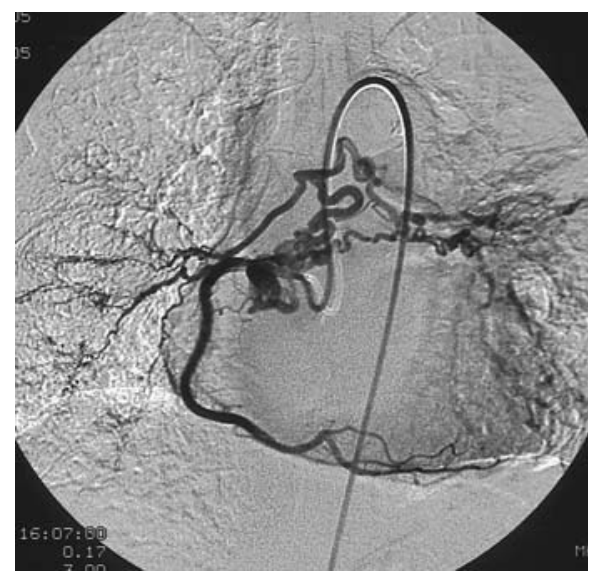

Fig. 2 Right coronary angiogram

(normal range, $0.0-0.2 \mathrm{ng} / \mathrm{ml}$ ). Selective coronary angiography was performed to rule out acute coronary syndrome (Fig. 2).

What is the diagnosis?

Readers are invited to supply one possible diagnosis via electronic means to: robert.hermans@uzleuven.be

The subject of the email should include 'Interpretation Corner' and the number 2009: 4a.

You should include your name, title, address, fax and phone number.

Deadline: one clear calendar month from distribution date.

Three months after the initial publication of the case history, the authors will publish the final diagnosis and a brief summary. The summary will describe exactly how the case was investigated at the host institution, how the diagnosis was established and the teaching points of the case in question. 